\title{
Bifidobacterium adolescentis (DSM 20083) and Lactobacillus casei (Lafti L26-DSL): Probiotics Able to Block the In Vitro Adherence of Rotavirus in MA104 Cells
}

\author{
Karem Prunella Fernandez-Duarte ${ }^{1} \cdot$ Nury Nathalia Olaya-Galán $^{1}$. \\ Sandra Patricia Salas-Cárdenas ${ }^{1}$ - Jazmin Lopez-Rozo ${ }^{1}$ • \\ Maria Fernanda Gutierrez-Fernandez ${ }^{1}$
}

Published online: 21 April 2017

(C) The Author(s) 2017. This article is an open access publication

\begin{abstract}
Rotavirus is the leading worldwide cause of gastroenteritis in children under five years of age. Even though there are some available vaccines to prevent the disease, there are limited strategies for challenging diarrhea induced by rotavirus infection. For this reason, researchers are constantly searching for other approaches to control diarrhea by means of probiotics. In order to demonstrate the ability of some probiotic bacteria to interfere with the in vitro rotavirus infection in MA104 cells, strains of Lactobacillus sp. and Bifidobacterium sp. were tested in MA104 cells before the viral infection. As a preliminary assay, a blocking effect treatment was performed with viable bacteria. In this screening assay, four of initial ten bacteria showed a slight reduction of the viral infection (measured by percentage of infection). L. casei (Lafti L26-DSL), L. fermentum(ATCC 9338), B. adolescentis (DSM 20083), and B. bifidum (ATCC 11863 ) were used in further experiments. Three different treatments were tested in order to evaluate protein-based metabolites obtained from mentioned bacteria: (i) cell exposure to the protein-based metabolites before viral infection, (ii) exposure to protein-based metabolites after viral infection, and (iii) coincubation of the virus and protein-based metabolites before viral infection to the cell culture. The best effect performed by protein-based metabolites was observed during the coincubation assay of the virus and protein-based metabolites before adding them into the cell culture. The results showed
\end{abstract}

Maria Fernanda Gutierrez-Fernandez mfgutier@javeriana.edu.co

1 Infectious Diseases Research Group, Department of Microbiology, Pontificia Universidad Javeriana, Carrera 7 \#40-62, (50-123), Bogota, Colombia
25 and $37 \%$ of infection in the presence of $L$. case $i$ and $B$. adolescentis respectively. These results suggest that the antiviral effect may be occurring directly with the viral particle instead of making a blocking effect of the cellular receptors that are needed for the viral entrance.

Keywords Rotavirus · Antiviral effect · Protein-based metabolites $\cdot$ Lactobacillus casei $\cdot$ Bifidobacterium adolescentis $\cdot$ Co-incubation

\section{Background}

Worldwide, acute diarrheal disease (ADD) remains as one of the most common diseases affecting people of all ages, but its frequency and severity are higher in children under the age of 5 [1]. About 600,000 children die every year as a consequence of rotavirus infection, with more than $80 \%$ of all rotavirusrelated deaths occurring in low-income countries in south Asia and sub-Saharan Africa [2]. Globally, rotavirus-related deaths represent approximately $5 \%$ of all deaths in children of this age. However, in other regions of developing countries, mortality is not so high but important rates of morbidity still remain in spite of the availability of a polyvalent vaccine worldwide [3].

Probiotics are defined as "lived microorganisms that, when administered in adequate amounts, confer a health benefit on the host" $[4,5]$. Some of these benefits have been established on human health in the infectious disease field: (i) interaction and enhancement of the immune system, (ii) production of antimicrobial substances, (iii) enhancement of the mucosal barrier function, and (iv) competition with enteropathogens [6-8]. Some studies have demonstrated the beneficial effect 
of probiotics against rotavirus infection [9, 10]. Most of them are clinical assays proving that the use of probiotics can lessen severity and duration of rotavirus diarrhea [11], whereas other studies are performed in vitro directed to the understanding of molecular and biochemical pathways associated with the mechanism employed by probiotics to accomplish the antiviral activity [12-14].

Even if most of these studies show the effectiveness of probiotics or their metabolic products on viral multiplication (both clinical and in vitro assays), some strategies have been established associated to the antiviral effect such as blocking effect, intracellular regulation, and immune response modulation [15-17]; however, evidence is not enough to clarify the mechanisms by which these processes occur, giving way to further studies in order to understand better the antiviral effect mediated by probiotic bacteria.

As a manner of fact, so as to advance the knowledge related to the strategies used by probiotics against viruses, we proposed as a hypothesis in which the probiotic bacteria were able to block in vitro rotavirus infection by altering the process of adhesion of the virus onto the cells. The aim of this study was to determine if the antiviral effect of probiotics was given by the competition of receptors on culture cells and whether this effect was caused by the whole and viable bacteria and/or was due to its protein-based metabolites.

\section{Materials and Methods}

\section{Cell Lines and Virus}

The MA-104 cell line (embryonic Rhesus monkey kidney cells) were grown in advanced DMEM supplemented with $4 \%$ fetal calf serum (Gibo, Invitrogen), L-glutamine ( $2 \mathrm{mmol} / \mathrm{L})$, antibiotic, and antimycotic, at $37{ }^{\circ} \mathrm{C}$ in $5 \% \mathrm{CO}_{2}$ atmosphere in tissue culture flasks until confluency. The cell culture medium was regularly changed. For the assays, 150,000 cells per well were placed in 24-well plates and incubated at the same conditions. After $24 \mathrm{~h}$ and $90 \%$ of confluence, each well contained about 500,000 cells.

Rotavirus RRV strain (Rhesus monkey) was kindly donated by Dr. Carlos Guerrero of the Universidad Nacional de Colombia. The infection was performed with a MOI of 5 and the virus was previously activated with trypsin $(10 \mu \mathrm{g} /$ $\mathrm{mL})$. The MOI of 5 was used in order to saturate the MA104 cell culture, simulating what could occur during a natural viral infection in mature enterocytes, where the amount of virus is greater than the amount of cells.

\section{Probiotic Bacteria and Growth Conditions}

L. casei (Lafti L26-DSL), L. rhamnosus (ATCC 7469), L. fermentum (ATCC 9338), L. plantarum (CECT 220),
L. acidophilus (Lafti L10-DSL), B. lactis (Lafti B94-DSL), B. breve (ATCC 15700), B. adolescentis (DSM 20083), B. bifidum (ATCC 11863), and B. dentium (DSM 20084) were activated in MRS broth at $37^{\circ} \mathrm{C}$ under anaerobic conditions and stored at $-80{ }^{\circ} \mathrm{C}$ in the same broth supplemented with $25 \%$ glycerol $(v / v)$ and skim milk $10 \%(w / v)$. The number of viable bacteria in $1 \mathrm{~mL}$ of bacterial culture was determined by measuring optical density at $580 \mathrm{~nm}$. The number was determined by extrapolation of the internal laboratory standard curve. For experimental approaches, bacteria cultures were centrifuged at $3000 \times \mathrm{g}$ for $10 \mathrm{~min}$ and bacteria were resuspended in DMEM for all the antiviral assays. The final bacterial suspension contained $1 \times 10^{8} \mathrm{CFU} / \mathrm{mL}$ as previously reported [18].

Bacteria were maintained under anaerobic conditions by streaking method in MRS solid culture media with AnaeroGen sachets (OXOID) in anaerobic jars. For experiments, bacteria were grown in MRS broth under anaerobic conditions as previously described by Hungate in 1969 [19]. Briefly, MRS broth was heated until boiling, and then gas exchange was performed with a constant flux of nitrogen $\left(\mathrm{N}_{2}\right)$ gas. A final gas exchange was performed with a mixture of 80:20 of nitrogen $\left(\mathrm{N}_{2}\right)$ and carbon dioxide $\left(\mathrm{CO}_{2}\right)$ in order to remove remaining oxygen present in the media.

\section{Recovery of Bacteria Protein-Based Metabolites}

Bacterial culture supernatants were obtained from growing bacterial cultures in $250 \mathrm{~mL}$ MRS broth under anaerobic conditions until the exponential growth of each bacterium was accomplished (recollection times differ between 8 and $10 \mathrm{~h}$ of bacterial growth) at $37^{\circ} \mathrm{C}$. Bacteria were removed by centrifugation at $3000 \times \mathrm{g}$ for $10 \mathrm{~min}$. Supernatants were recovered and filtered through a pore of $0.22 \mu \mathrm{m}$. Protein-based metabolites were precipitated with $10 \%$ PEG $(w / v)$ overnight. After that, concentric centrifugations at $16,000 \times g, 4{ }^{\circ} \mathrm{C}$ for $30 \mathrm{~min}$ were performed with the aim of concentrating the protein-based metabolites present in the supernatants. Proteins were resuspended in $2.5 \mathrm{~mL}$ of sterile PBS and stored at $-20{ }^{\circ} \mathrm{C}$ until use. The proteins were quantified using the BCA kit Thermo Scientific. For both cytotoxicity and antiviral assays, a free bacteria broth control was considered, which was also precipitated with PEG and compared with metabolites for viability and with the positive control in the antiviral assays.

\section{Cytotoxicity Assays}

To perform biological assays, MA-104 cells were separately seeded in 96-well plates until confluence. Cytotoxic effect was tested for each probiotic bacterium and protein-based metabolites by tenfold serial dilutions added to the confluent cells. Cells exposed to bacteria or protein-based metabolites were incubated for $90 \mathrm{~min}$ at $37^{\circ} \mathrm{C}$. After that, cells were washed 
twice with PBS and were incubated for $24 \mathrm{~h}$ at $37^{\circ} \mathrm{C}$ with $5 \%$ $\mathrm{CO}_{2}$. Cytotoxicity effect was determined by $0.4 \%$ trypan blue visualized in a light microscope for viable bacteria. For protein-based metabolites, cytotoxicity was tested using MTT salts (SIGMA-Aldrich, Saint Louis), in order to determine the formation of formazan products detected in a Multiskan MCC/340 (Thermo Fisher Scientific, Waltham) spectrophotometer at a wavelength of $540 \mathrm{~nm}$. Cytotoxicity assays for whole and viable bacteria were tested at concentrations between $10^{6}$ and $10^{8} \mathrm{FCU} / \mathrm{mL}$ as reported by Botic et al. [18]. Protein-based metabolites were tested in ranges between 10 and $1000 \mu \mathrm{g} / \mathrm{mL}$ diluted in DMEM as well as pure metabolite.

\section{Antiviral Assays}

Inhibition of viral infection by the whole and viable bacteria: Ten probiotic bacteria [20] were tested against RV infection by the principle of blocking the viral entrance to the cells. For these experiments, cells were first incubated with viable probiotic bacteria $\left(500 \mu \mathrm{L}, 10^{8} \mathrm{CFU} / \mathrm{mL}\right)$ for $90 \mathrm{~min}$ at $37^{\circ} \mathrm{C}$ and $5 \% \mathrm{CO}_{2}$. After incubation, cell cultures were washed to remove unattached bacteria from the cells with DMEM without supplements and monolayers were challenged with RV infection for $10 \mathrm{~h}$ at $37{ }^{\circ} \mathrm{C}$ and $5 \% \mathrm{CO}_{2}$. Percentage of viral infection was measured by flow cytometry. These experiments were the preliminary tests to select the bacteria with major activity with the aim of using them in further assays.

Inhibition of viral infection by bacterial protein-based metabolites (pre-treatment): Cells were first incubated with $100 \mu \mathrm{g} / \mathrm{mL}$ of each metabolite for $90 \mathrm{~min}$. After this time, the unbounded protein-based metabolites were washed out from the cells with DMEM without supplements and monolayers were challenged with $\mathrm{RV}$ infection for $10 \mathrm{~h}$ at $37^{\circ} \mathrm{C}, 5 \% \mathrm{CO}_{2}$.

Inhibition of viral infection due to a co-incubation assay: Bacterial protein-based metabolites were first co-incubated with RV (previously activated with $10 \mu \mathrm{g} / \mathrm{mL}$ trypsin) in DMEM for $60 \mathrm{~min}$ at $37{ }^{\circ} \mathrm{C}$ and $5 \% \mathrm{CO}_{2}$. After this time, the mixture was placed in contact with the MA104 cells for $1 \mathrm{~h}$ at $37{ }^{\circ} \mathrm{C}$ and $5 \% \mathrm{CO}_{2}$, and then the excess of inoculum was washed and assays were incubated until $10 \mathrm{~h}$ of post-infection.

Intracellular effect of the protein-based metabolites of probiotic bacteria against viral infection (post-infection assay): MA104 cells were first infected with the virus as previously described, and after removing the viral inoculum, cells were washed with PBS and were exposed to bacterial protein-based metabolites $(100 \mu \mathrm{g} / \mathrm{mL})$ per $1 \mathrm{~h}$. Unbounded protein-based metabolites were washed, and cells were incubated until $10 \mathrm{~h}$ as mentioned before.

For all the antiviral assays, positive and negative controls were included. Positive controls were MA104 cells infected with RRV at a MOI of 5 without any treatment. Negative controls were MA104 cells grown simultaneously in the experiments with DMEM without supplements in the culture. Antiviral assays were performed by three independent assays and duplicate each.

\section{Flow Cytometry: Detection of Viral Infection}

The viral growth was determined by flow cytometry in all the antiviral assays. Cells were dissociated with trypsin, placed in $1.5-\mathrm{mL}$ conical tubes, centrifuged at $3000 \times g$, and resuspended in $500 \mu \mathrm{L}$ sterile PBS-EDTA [21]. Cells were fixed for $15 \mathrm{~min}$ with $2 \%$ paraformaldehyde. After removing this paraformaldehyde, cells were washed with PBS and permeabilized with Triton X-100 0.3\%. For intracellular viral detection, an antiTLP polyclonal antibody produced in rabbit, with a titer of $1 /$ 3000 (kindly donated by Dr. Carlos Guerrero, Universidad Nacional), directed to VP6 proteins of the virus, was used. Then, as a secondary antibody, an anti-Rabbit IgG Alexa Fluor 488 (Invitrogen) diluted 1/2500 was used; staining was performed at room temperature in dark conditions. Cells were washed twice with PBS and were resuspended in FACSflow until analysis. A FACS Aria II cytometer (Becton Dickinson) was used for analysis, where percentages of positives cells were included. Further analyses were performed with Flow-Jo software.

\section{Statistical Analysis}

ANOVA and Dunnett's tests were used as a parametric statistical analysis in order to find if the percentage of infected cells and the presence of the viral antigen inside the cells treated with probiotics or its protein-based metabolites were significant compared with the positive control $(p<0.05)$.

\section{Results}

\section{Cytotoxicity Tests}

Cytotoxicity tests were performed to determine the maximum concentration at which bacteria or protein-based metabolites can be used on MA104 cell line. For whole and viable bacteria, it was found that a concentration of $1 \times 10^{8} \mathrm{CFU} / \mathrm{mL}$ of bacteria did not show toxicity over the MA104 cell line, shown by the trypan blue stain, where cell viability was higher than $90 \%$ in all the cases. Viable bacteria results show that the ten probiotic strains were not toxic for MA104 cell line and could be used in further experiments.

In the case of the bacterial protein-based metabolites, folded dilutions in DMEM were analyzed with MTT technique, where in general, a concentration of $100 \mu \mathrm{g} / \mathrm{mL}$ for all the metabolites was atoxic for the MA104 cell culture. Viability was obtained between 90 and $100 \%$ in the presence of the four metabolites. In contrast, when testing pure 
metabolites (without dilutions in DMEM), high toxic effects were obtained (Fig. 1).

\section{Preliminary Screening of Bacteria with Potential Antiviral Activity}

Growth conditions of the ten probiotic strains are shown in Table 1 . In the preliminary assay against RV infection, non-significant results were obtained; however, the 10 tested bacteria, L. casei, L. fermentum, $B$. adolescentis, and B. bifidum, were the ones with highest antiviral activity by a tentative blocking effect of the viral entrance. A reduction of the viral infection of $31,37,42$, and $24 \%$, respectively, measured by flow cytometry, was obtained. In contrast, viral infection in the positive control (MA104 cells infected with the virus) was around of $90 \%$ of positive cells. These four bacterial strains were selected to continue further inhibition experiments using primary protein-based metabolites derived from their growth (Fig. 2, viable bacteria).

After selection of the four strains with the best antiviral effect, the metabolites of each bacteria were recovered. After precipitation with PEG, quantification was performed by BCA technique. Each metabolite was obtained in three independent culture batches for the antiviral assays. Results of the amount of protein could be seen in Table 2.

\section{Antiviral Activity of Protein-Based Metabolites}

\section{Inhibition of Viral Infection by Bacterial Protein-Based Metabolites: Pre-Treatment Assay}

Pre-treatment period of 90 min on MA104 cells with probiotic protein-based metabolites followed by viral infection did not show any differences between the treatments and the positive control. Percentage of infection in the treatments was between 70 and $75 \%$, which was the same as that in the positive control $(71 \%)$. These results suggest that the protein-based metabolites were not significant in performing a blocking effect of cellular receptors in the viral infection (Fig. 2, pre-treatment).

\section{Reduction of the Viral Infectivity: Co-Incubation Assay between Virus and Protein-Based Metabolites}

To determine whether probiotic protein-based metabolites were able to interact directly with the virus, and thus affect the viral attachment to the cells, the co-incubation assay was performed. The results showed a significant decrease in the viral infection. The percentage of infected cells in the presence of the B. adolescentis (26\%) decreased markedly in comparison with the positive control $(80 \%)$. A similar behavior was found in the presence of $L$. casei, where the percentage of infected cells was significantly reduced to a $38 \%$. Likewise, the protein-based metabolites of the other bacteria also
Fig. 1 Cytotoxicity effect of bacterial metabolites tested in MA104 cells. a $L$. casei. b L. fermentum. $\mathbf{c} B$. adolescentis. d B. bifidum. Notice $100 \%$ of cell viability when using $100 \mu \mathrm{g} / \mathrm{mL}$ with the metabolites of the four bacteria
A
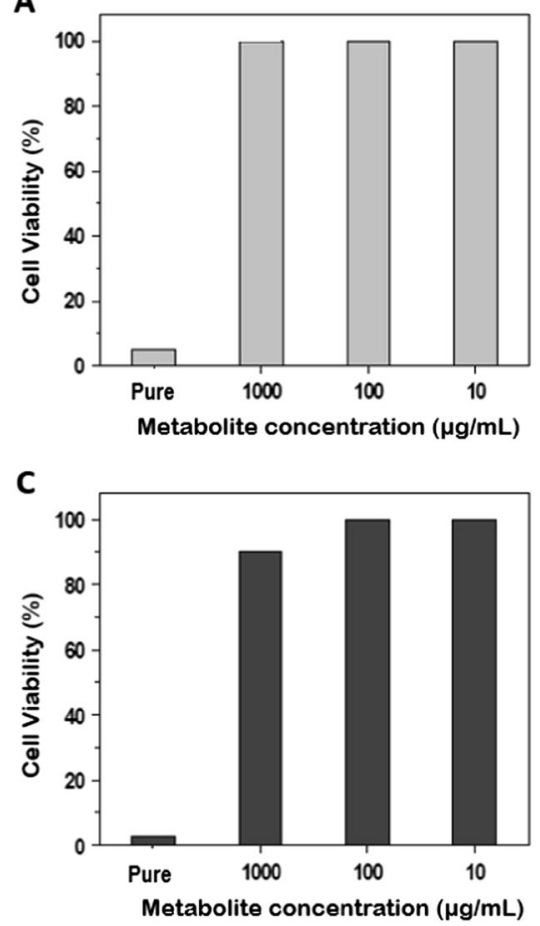

B

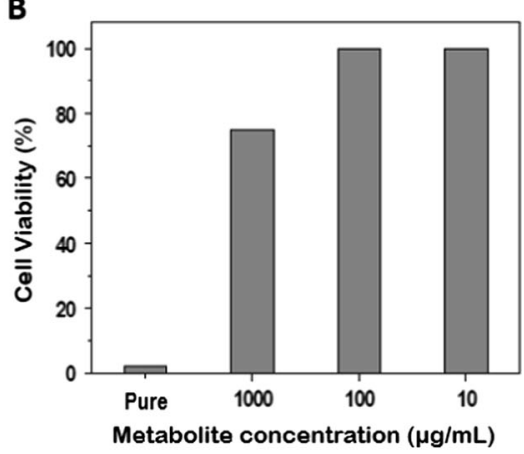

D

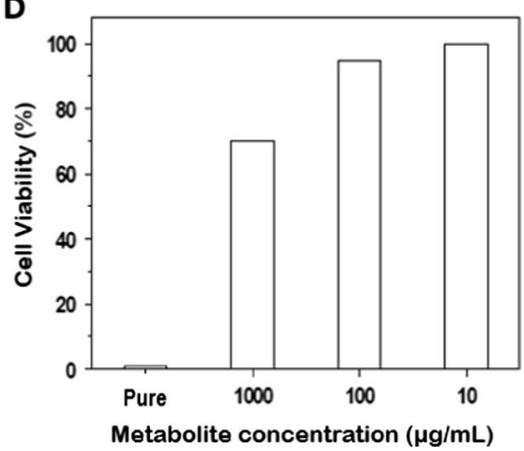


Table 1 Conditions of bacteria cultures during exponential phase and preliminary antiviral assays

\begin{tabular}{|c|c|c|c|c|}
\hline \multirow[t]{2}{*}{ Probiotic strains } & \multicolumn{3}{|c|}{ Exponential growth conditions } & \multirow{2}{*}{$\begin{array}{l}\text { Preliminary assay } \\
\text { Percentage of viral } \\
\text { infection }^{\text {a }}\end{array}$} \\
\hline & $\begin{array}{l}\text { Time } \\
\text { (hours) }\end{array}$ & $\begin{array}{l}\text { OD } \\
(580 \mathrm{~nm})\end{array}$ & $\begin{array}{l}\log _{10} \mathrm{CFU} / \\
\mathrm{mL}\end{array}$ & \\
\hline L. casei (Lafti L26-DSL) & 8 & 0.43 & 7.94 & $69 \%$ \\
\hline L. rhamnosus (ATCC 7469) & 8 & 0.289 & 7.43 & $80 \%$ \\
\hline L. fermentum (ATCC 9338) & 8 & 0.47 & 6.67 & $63 \%$ \\
\hline L. plantarum (CECT 220) & 8 & 0.403 & 8.31 & $76 \%$ \\
\hline $\begin{array}{l}\text { L. acidophilus (Lafti } \\
\text { L10-DSL) }\end{array}$ & 10 & 0.202 & 6.94 & $78 \%$ \\
\hline B. lactis & 10 & 0.09 & 6.23 & $75 \%$ \\
\hline \multicolumn{5}{|l|}{ (Lafti B94-DSL) } \\
\hline B. breve (ATCC 15700) & 6 & 0.1 & 6.83 & $72 \%$ \\
\hline B. adolescentis (DSM 20083) & 8 & 0.054 & 6.68 & $58 \%$ \\
\hline B. bifidum (ATCC 11863) & 6 & 0.151 & 4.82 & $67 \%$ \\
\hline B. dentium (DSM 20084) & 8 & 0.6 & 7.86 & $80 \%$ \\
\hline
\end{tabular}

${ }^{\text {a }}$ Positive control for preliminary assays had a $90 \%$ of infected cells with RRV showed a significant result $(P<0.05)$ decreasing the percentage of infected cells to 54 and 50\% (Fig. 2, co-incubation).

\section{Effect of Protein-Based Metabolites after Viral Infection}

In the last strategy analyzed, it could be observed that the single metabolite that achieved a significant reduction in the viral infection was the one obtained from $B$. adolescentis with a $P$ value $=0.001$. The other three protein-based metabolites did not show any activity by this assay (Fig. 2, post-treatment).

\section{Discussion}

Taking into account that rotavirus infection is still one of the most important diseases in developing countries that affect children under the age of five [22,23], all the possible alternatives directed to improve the life quality of children should be considered. Thus, the use of probiotics to counteract the effect of rotavirus in the human population arises as an important strategy to manage the disease.

Although probiotics have been reported in several studies against rotavirus infection $[13,14,17,18]$, the specific mechanism by which the antiviral effect is mediated remains unclear. Even if probiotics are also used in the prevention and therapy of diarrhea, non-standardized conditions have been established in clinical trials, as well as the definition of the probiotic strains with best results [11].

Particularly in this study, the objective was to determine whether probiotics or their protein-based metabolites had the ability to interfere with the first steps of the viral cycle, which are viral adhesion or penetration, being fundamental steps for the viral infection [24]. The first approach of this work was evaluated with whole and viable bacteria in an early stage of the viral cycle. It was expected that viable bacteria attached to the cell surface in order to colonize the MA104 cell
Fig. 2 Effect of L. casei, L. fermentum, B. adolescentis, and B. bifidum and its metabolite products on RV infection in MA104 cells. (dark gray) Screening assay: viable bacteria, blocking effect. Evaluation of antiviral treatments: protein-based metabolites, (light gray) pretreatment; (gray) co-incubation; (black) post-infection. Statistical analysis showed significant results in the co-incubation treatment when compared with positive control $(A)$ (letters $A B$; $p=0.005$; letter $B ; p=0.001$ )

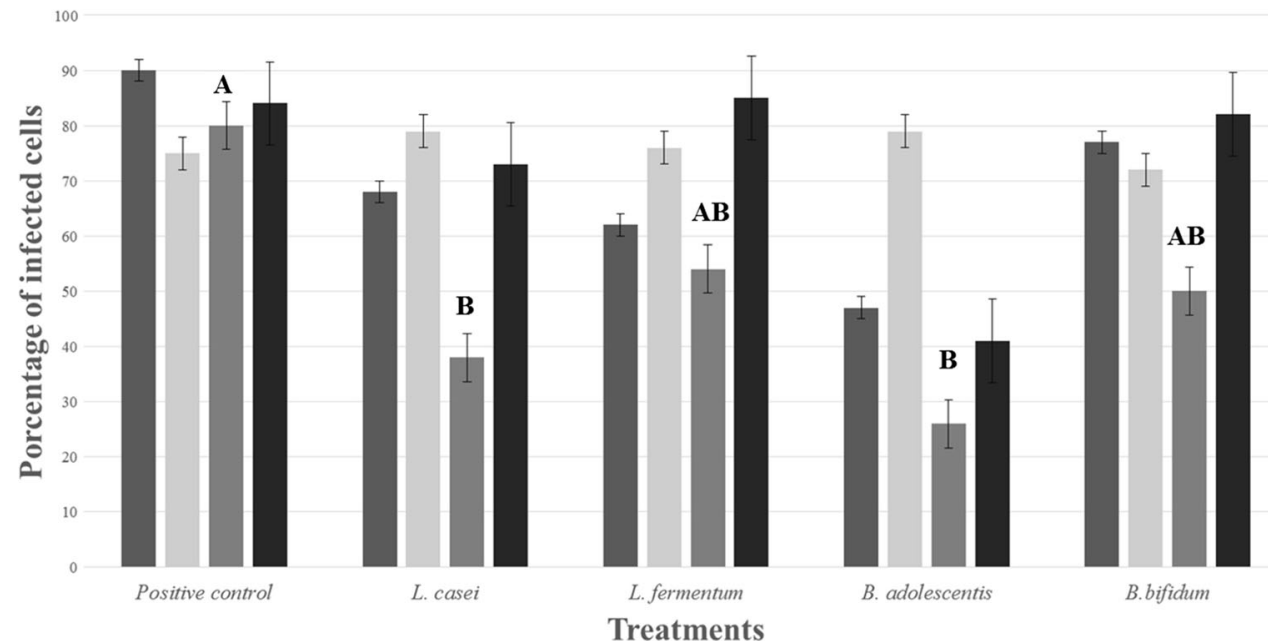


Table 2 Protein-based metabolites quantification after precipitation with PEG

\begin{tabular}{lrccr}
\hline & \multicolumn{4}{l}{ Probiotic metabolites concentrations $(\mu \mathrm{g} / \mathrm{mL})$} \\
\cline { 2 - 5 } Batch & L. casei & L. fermentum & B. adolescentis & B. bifidum \\
\hline 1 & 1001.33 & 742.17 & 1040.22 & 758.56 \\
2 & 706.06 & 1680.78 & 694.94 & 1540.22 \\
3 & 1214.94 & 1376.61 & 556.06 & 1716.06 \\
\hline
\end{tabular}

Data is shown as mean of three independent measures for each bacteria/ batch

monolayers and thus cellular receptors involved in in vitro adhesion [18]. In the preliminary results of the screening assays, a blockage of the viral entrance was observed and could agree with the proposal of some other studies regarding the antiviral effect of probiotics [25-29].

Even if specific receptors were not tested, these preliminary results showed a reduction in the viral infection measured by flow cytometry in four out of the ten probiotic strains tested. One of these four bacteria was $B$. adolescentis, which has been previously reported as a potential microorganism with an antiviral activity against different viruses [14, 30-32].

Now, in spite of the wide use of probiotics in many fields, there are few cases where the use of viable bacteria could lead to opportunistic infections, allergic reactions, or autoimmune responses [33]. This is the reason why the use of probioticderived products has arisen in a new field denominated metabiotics [34]. Experimental approaches tested with these probiotic-derived products have also shown interesting results [35].

In this study, the probiotic strains chosen from the screening assay were L. casei, L. fermentun, B. adolescentis, and B. bifidum, where protein-based metabolic products were tested in further experiments. From the three different strategies evaluated (pre-treatment, co-incubation, and post-infection), the co-incubation assay of viral particles and protein-based metabolites showed the best results in the antiviral activity approach in comparison with the other treatments. It prevented the viral adhesion and/or penetration into the MA104 cells maybe because of a direct interaction of the protein-based metabolites with the external viral proteins such as VP7 or VP4. It is important to take into account that all experiments were performed with trypsin-activated viral particles, a fundamental process for a cleavage step of the viral proteins necessary for viral entrance to the host cell [36].

On the other hand, in the case of pre-treatment and postinfection assays, it was expected that the antiviral activity was mediated by a mechanism directed to the cells instead of affecting the viral particle. The hypothesis is that direct interactions with the cellular receptors or intracellular regulating processes could be happening. Here, in the first case, according to the suggested mechanism of probiotics [18, 37], it was expected that the interaction with cellular receptors of protein-based metabolites could block the attachment of the virus to the cell surface, and thus, the viral entrance could not be performed. In the second case, it was proposed to produce an antiviral activity associated with intracellular regulation as it was previously reported for another strain of $B$. adolescentis [38].

With this study, it could be said that protein-based metabolites obtained from $L$. casei and B. adolescentis were able to block rotavirus entrance by a direct effect on the viral particle, in contrast to the proposed hypothesis. It is possible that adhesion process to the MA104 cell receptors could not be efficiently performed due to an alteration in the external viral proteins; results were observed in comparison with the positive control.

Hence, results obtained in this study are a preliminary approach in order to continue analyzing the possible mechanism exerted by probiotic bacteria. An important fact to take into account in further studies is to evaluate if it could be a dosedependent activity of probiotic metabolites, taking into account that in this study, we used high concentrations of the metabolites. Therefore, an optimization of the process could be obtained if lower concentrations are also able to perform antiviral activity.

These results contribute to strengthening the knowledge that supports the activity of probiotic bacteria against gastrointestinal viral infections. Several mechanisms have been proposed, but co-infection strategy could be considered as a novel approach against rotavirus. This strategy could be a possible alternative directed to crops that could be contaminated with $\mathrm{RV}$ on field. Further studies are needed to completely understand the specific mechanisms involved in the antiviral activity of probiotics; in vivo and clinical approaches are necessary in order to verify its antiviral activity. In the future, it could be proposed a simple and inexpensive biological product, with potential antiviral activity dispensed as a dietary supplement or maybe in a drug formulation.

Acknowledgments The authors want to acknowledge the Flow Cytometry Unit of the Specialized Immunology Center from the Pontificia Universidad Javeriana which supported the development of the research.

Author's Contributions KPF performed the experimental assays, data analysis, and helped write the manuscript.

NOG participated in the experimental assays and in the writing, edition, and revision of the manuscript.

SSC participated in the experimental assays.

JLP participated in the experimental assays.

MFG wrote the research project and performed data analysis and the writing and revising of the manuscript.

\section{Compliance with Ethical Standards}

Competing Interest The authors declare that they have no competing interest. 
Ethical Statement This article does not contain any studies with human participants or animals performed by any of the authors.

Funding This study was funded by Colciencias in the research project entitled "Búsqueda y caracterización preliminar de moléculas obtenidas a partir de bacterias probióticas para usarlas como posibles inhibidores de la infección in vitro por rotavirus y astrovirus" in the national call 629 from 2009 and by Pontificia Universidad Javeriana.

Open Access This article is distributed under the terms of the Creative Commons Attribution 4.0 International License (http:// creativecommons.org/licenses/by/4.0/), which permits unrestricted use, distribution, and reproduction in any medium, provided you give appropriate credit to the original author(s) and the source, provide a link to the Creative Commons license, and indicate if changes were made.

\section{References}

1. Parashar UD, Hummelman EG, Bresee JS et al (2003) Global illness and deaths caused by rotavirus disease in children. Emerg Infect Dis 9:565-572

2. Farthing M, Salam MA, Lindberg G et al (2013) Acute diarrhea in adults and children: a global perspective. J Clin Gastroenterol 47: 12-20. doi:10.1097/MCG.0b013e31826df662

3. Chen S-C, Tan L-B, Huang L-M, Chen K-T (2012) Rotavirus infection and the current status of rotavirus vaccines. J Formos Med Assoc 111:183-193. doi:10.1016/j.jfma.2011.09.024

4. FAO (2001) Probiotics in food. Food Nutr Pap 85:71. doi:10.1201/ 9781420009613.ch16

5. Hill C, Guarner F, Reid G et al (2014) Expert consensus document: the international Scientific Association for Probiotics and Prebiotics consensus statement on the scope and appropriate use of the term probiotic. Nat Rev Gastroenterol Hepatol 11:9. doi:10.1038/ nrgastro.2014.66

6. Wanke M, Szajewska H (2014) Probiotics for preventing healthcare-associated diarrhea in children: a meta-analysis of randomized controlled trials. Pediatr Pol 89:8-16. doi:10.1016/j.pepo. 2013.12.003

7. Sánchez B, Urdaci MC, Margolles A (2010) Extracellular proteins secreted by probiotic bacteria as mediators of effects that promote mucosa-bacteria interactions. Microbiology 156:3232-3242. doi: 10.1099/mic.0.044057-0

8. Salminen S, Nybom S, Meriluoto J et al (2010) Interaction of probiotics and pathogens-benefits to human health? Curr Opin Biotechnol 21:157-167. doi:10.1016/j.copbio.2010.03.016

9. Vlasova AN, Chattha KS, Kandasamy S et al (2013) Lactobacilli and bifidobacteria promote immune homeostasis by modulating innate immune responses to human rotavirus in neonatal gnotobiotic pigs. PLoS One 8:e76962. doi:10.1371/journal.pone.0076962

10. Huang Y-F, Liu P-Y, Chen Y-Y et al (2014) Three-combination probiotics therapy in children with salmonella and rotavirus gastroenteritis. J Clin Gastroenterol 48:37-42. doi:10.1097/MCG. 0b013e31828flc6e

11. Ahmadi E, Alizadeh-Navaei R, Rezai MS (2015) Efficacy of probiotic use in acute rotavirus diarrhea in children: a systematic review and meta-analysis. Casp J Intern Med 6:187-195. doi:10. 1023/A:1020501202369

12. Chenoll E, Rivero M, Codoñer FM et al (2015) Complete genome sequence of Bifidobacterium longum subsp. infantis strain CECT 7210 , a probiotic strain active against rotavirus infections. Genome Announc 3:e0105-e00115. doi:10.1128/genomeA.00105-15
13. Lee DK, Park JE, Kim MJ et al (2015) Probiotic bacteria, B. longum and $\mathrm{L}$. acidophilus inhibit infection by rotavirus in vitro and decrease the duration of diarrhea in pediatric patients. Clin Res Hepatol Gastroenterol 39:237-244. doi:10.1016/j.clinre.2014.09. 006

14. Olaya Galán NN, Ulloa Rubiano JC, Velez Reyes FA et al (2016) In vitro antiviral activity of Lactobacillus casei and Bifidobacterium adolescentis against rotavirus infection monitored by NSP4 protein production. J Appl Microbiol 120:1041-1051. doi:10.1111/jam. 13069

15. Kang JY, Lee DK, Ha NJ, Shin HS (2015) Antiviral effects of Lactobacillus ruminis SPM0211 and Bifidobacterium longum SPM1205 and SPM1206 on rotavirus-infected Caco-2 cells and a neonatal mouse model. J Microbiol 53:796-803. doi:10.1007/ s12275-015-5302-2

16. Wen K, Li G, Bui T et al (2012) High dose and low dose Lactobacillus acidophilus exerted differential immune modulating effects on $\mathrm{T}$ cell immune responses induced by an oral human rotavirus vaccine in gnotobiotic pigs. Vaccine 30:1198-1207. doi: 10.1016/j.vaccine.2011.11.107

17. Muñoz JAM, Chenoll E, Casinos B et al (2011) Novel probiotic Bifidobacterium longum subsp. infantis CECT 7210 strain active against rotavirus infections. Appl Environ Microbiol 77:87758783. doi:10.1128/AEM.05548-11

18. Botić T, Klingberg TD, Weingartl H, Cencic A (2007) A novel eukaryotic cell culture model to study antiviral activity of potential probiotic bacteria. Int J Food Microbiol 115:227-234. doi:10.1016/ j.ijfoodmicro.2006.10.044

19. Hungate RE (1969) A roll tube method for cultivation of strict anaerobes. In: Methods Microbiol. Elsevier, London, pp 117-132

20. Gomes AMP, Malcata FX (1999) Bifidobacterium spp. and Lactobacillus acidophilus: biological, biochemical, technological and therapeutical properties relevant for use as probiotics. Trends Food Sci Technol 10:139-157. doi:10.1016/S0924-2244(99) 00033-3

21. Didsbury A, Wang C, Verdon D et al (2011) Rotavirus NSP4 is secreted from infected cells as an oligomeric lipoprotein and binds to glycosaminoglycans on the surface of non-infected cells. Virol J 8:551. doi:10.1186/1743-422X-8-551

22. Tate JE, Burton AH, Boschi-Pinto C et al (2012) 2008 estimate of worldwide rotavirus-associated mortality in children younger than 5 years before the introduction of universal rotavirus vaccination programmes: a systematic review and meta-analysis. Lancet Infect Dis 12:136-141. doi:10.1016/S1473-3099(11)70253-5

23. Velázquez RF, Linhares AC, Muñoz S et al (2017) Efficacy, safety and effectiveness of licensed rotavirus vaccines: a systematic review and meta-analysis for Latin America and the Caribbean. BMC Pediatr 17:14. doi:10.1186/s12887-016-0771-y

24. Lentz TL, Dimmock NJ, Tardieu M et al (1988) Binding of viral attachment protein to host-cell receptor: the Achilles heel of infectious viruses. Trends Pharmacol Sci 9:247-252. doi:10.1016/01656147(88)90154-X

25. Weizman Z, Asli G, Alsheikh A (2005) Effect of a probiotic infant formula on infections in child care centers: comparison of two probiotic agents. Pediatrics 115:5-9. doi:10.1542/peds.2004-1815

26. Salazar-Lindo E, Miranda-Langschwager P, Campos-Sanchez M et al (2004) Lactobacillus casei strain GG in the treatment of infants with acute watery diarrhea: a randomized, double-blind, placebo controlled clinical trial [ISRCTN67363048]. BMC Pediatr 4:18. doi:10.1186/1471-2431-4-18

27. Erdoğan O, Tanyeri B, Torun E et al (2012) The comparition of the efficacy of two different probiotics in rotavirus gastroenteritis in children. J Trop Med 2012:787240. doi:10.1155/2012/787240

28. Misra S, Sabui TK, Pal NK (2009) A randomized controlled trial to evaluate the efficacy of lactobacillus GG in infantile diarrhea. J Pediatr 155:129-132. doi:10.1016/j.jpeds.2009.01.060 
29. Chen C-C, Kong M-S, Lai M-W et al (2010) Probiotics have clinical, microbiologic, and immunologic efficacy in acute infectious diarrhea. Pediatr Infect Dis J 29:135-138

30. An HM, Lee DK, Kim JR et al (2012) Antiviral activity of Bifidobacterium adolescentis SPM 0214 against herpes simplex virus type 1. Arch Pharm Res 35:1665-1671. doi:10.1007/ s12272-012-0918-9

31. Lee DK, Kang JY, Shin HS et al (2013) Antiviral activity of Bifidobacterium adolescentis SPM0212 against hepatitis B virus. Arch Pharm Res 36:1525-1532. doi:10.1007/s12272-013-0141-3

32. Kim MJ, Lee DK, Park JE et al (2014) Antiviral activity of Bifidobacterium adolescentis SPM1605 against Coxsackievirus B3. Biotechnol Biotechnol Equip 28:681-688. doi:10.1080/ 13102818.2014.945237

33. Butel M-J (2014) Probiotics, gut microbiota and health. Médecine Mal Infect 44:1-8. doi:10.1016/j.medmal.2013.10.002
34. Shenderov B a (2013) Metabiotics: novel idea or natural development of probiotic conception. Microb Ecol Health Dis 24:1-8. doi: 10.3402/mehd.v24i0.20399

35. Al Kassaa I, Hober D, Hamze M et al (2014) Antiviral potential of lactic acid bacteria and their bacteriocins. Probiotics Antimicrob Proteins 6:177-185. doi:10.1007/s12602-014-9162-6

36. Gilbert JM, Greenberg HB (1998) Cleavage of rhesus rotavirus VP4 after arginine 247 is essential for rotavirus-like particle-induced fusion from without. J Virol 72:5323-5327

37. Bermudez-Brito M, Plaza-Díaz J, Muñoz-Quezada S et al (2012) Probiotic mechanisms of action. Ann Nutr Metab 61:160-174. doi: 10.1159/000342079

38. Cha M-K, Lee D-K, An H-M et al (2012) Antiviral activity of Bifidobacterium adolescentis SPM1005-a on human papillomavirus type 16. BMC Med 10:72. doi:10.1186/1741-7015-10-72 